\title{
DOIS EM UMA CARNE: IGREJA E SEXUALIDADE NA HISTÓRIA
}

\section{Two in a flesh: Church and sexuality in the history}

Fábio Augusto Scarpim*

PELAJA, Margherita; SCARAFFIA, Lucetta. Due in una carne: Chiesa e sessualità nella storia. Bari: Editora Laterza, 2014. 322p.

O livro que se apresenta é resultado do trabalho de duas historiadoras com posicionamentos ideológicos distintos, mas que juntas se propõe a interrogar, verificar e reexaminar estereótipos enraizados na cultura ocidental, como aquele que atribui ao cristianismo primeiro, e depois a Igreja Católica, uma substancial sexofobia. Com um trabalho de pesquisa minucioso, as autoras propõem uma via de explicação que escapa as análises superficiais de um tema tão delicado e controverso como a relação entre Igreja e sexualidade.

O tema da sexualidade é um nodo central na história da Igreja, tanto que os debates a seu respeito renderam intensos e acalorados debates nos mais importantes sínodos e concílios do catolicismo, desde os primeiros séculos até o Vaticano II. Extrapolando, no momento atual novamente o tema volta à tona por conta da realização do Sínodo da Família, iniciado em outubro de 2014 e a ser concluído ao final de 2015. O pensamento moderno secularizado relegou a sexualidade a uma questão do indivíduo enquanto o pensamento católico tenta recuperar uma dimensão espiritual cunhada no início do cristianismo.

Margherita Pelaja é laica. Uma historiadora com militância no feminismo e dedicada ao estudo da história das mulheres. Junto

Doutorando em História pelo PPGHIS-UFPR. 
a outras estudiosas é fundadora da Revista Memoria, um importante periódico dos estudos de gênero na Itália. Tem se dedicado principalmente ao estudo da interação das mulheres e da família com os aparatos judiciários entre os séculos XVIII e XX. Já Lucetta Scaraffia é professora de História Contemporânea na Universidade de Roma La Sapienza e membro do Comitê Nacional de Bioética. Possui uma longa trajetória como historiadora das mulheres e do feminismo. Nos últimos vinte anos, se sentindo apaixonadamente católica, têm dedicado suas pesquisas sobre a relação entre as mulheres e a vida religiosa. As trajetórias e os posicionamentos das duas historiadoras, embora diversos, não impediram de produzir um trabalho estimulante e fecundo. A perspectiva mais social de Pelaja, e a visão cultural e teórica de Scaraffia tornam a obra uma instigante reconstrução do discurso católico sobre a sexualidade.

O livro tem como objetivo reconstruir o discurso e a política da Igreja Católica sobre a sexualidade partindo dos primeiros escritos do cristianismo até a publicação da Carta Encíclica Humanae Vitae pelo papa Paulo VI em 1968. Dessa maneira, oferecem uma contribuição inédita à historiografia sobre tal tema, pois, diferentemente de outros trabalhos que privilegiaram períodos e aspectos específicos da sexualidade (contracepção, masturbação, entre outros) as autoras fazem um sobrevôo em praticamente vinte séculos de história focando na relação entre norma e transgressão, bem como sua reverberação na arte, nos símbolos e no imaginário.

As autoras se posicionam de maneira crítica as visões correntes que atribuem à Igreja Católica uma atitude repressiva constante e generalizada sobre o sexo. O lugar comum é sólido: para o católico o prazer é culpa e o sexo é pecado. Deve ser praticado com parcimônia, no matrimônio com fins voltados exclusivamente a procriação. Entretanto, essa visão extremamente pessimista e negativa da sexualidade não é homogênea ao longo da história e nem corresponde aos significados atribuídos pelo cristianismo na sua origem. 
Do ponto de vista teológico o cristianismo colocou o sexo sobre um plano completamente novo, muito diferente do aspecto lúdico atribuído pelos gregos e romanos. Nessa direção, ligação sexual entre um homem e uma mulher derivaria da encarnação, a metáfora do vínculo entre a alma e Deus, da união entre Cristo e a Igreja, a antecipação do prazer do amor que se viverá no paraíso. O cristianismo vem dar um significado espiritual ao ato sexual carregando de uma importância e de uma luz que o absolveria da suspeita e do desprezo dado, por exemplo, pelos estoicos. Se esta ligação é permeada de significados espirituais, símbolo da unidade indissolúvel entre a alma e o corpo, a metáfora da união entre Cristo e a Igreja como salientou o apóstolo Paulo, deveria ser objeto de atenção e regulamentada com severidade. Assim, o governo da sexualidade não diria respeito apenas ao governo do corpo, mas também da alma. Tal premissa constitui um importante fio condutor utilizado pelas autoras para pensar os posicionamentos e atitudes da Igreja em relação à sexualidade.

O livro é dividido em seis partes. Embora a organização seja cronológica a obra não apresenta uma visão necessariamente linear do desenvolvimento do discurso católico, mas registra avanços, saltos e recuos na cronologia. O texto é construído a partir de uma rica variedade de fontes tais como: textos literários, filosóficos, jurídicos e religiosos, documentos judiciais, iconografia, bem como uma vasta revisão bibliográfica especializada. Do ponto de vista conceitual é importante destacar que as autoras trabalham com as definições do pensamento católico em relação aos atos conjugais e não conjugais (entre a norma e a sua transgressão) que contemplam uma dimensão ampla da sexualidade. Já do ponto de vista metodológico, que contribuiu sobremaneira para a organização da estrutura do livro, valorizam uma perspectiva histórico-teológica. Procuram compreender como e de que modo todo o arsenal discursivo criado pelo cristianismo e depois pela Igreja (as Sagradas Escrituras, os tratados, as obras de formação do clero e dos fieis, a iconografia) encontrava aplicação prática no governo das almas. 
O primeiro capítulo intitulado: O corpo, as pulsões têm como ponto de partida a visão paulina sobre o sexo passando pelos escritos mais importantes do cristianismo como Graciano, Tertuliano, Jerônimo, Agostinho até as discussões sobre casamento e celibato empreendidas durante a Reforma Gregoriana dos séculos XI e XII. Nesse capítulo as autoras destacam a profunda mudança feita pelo cristianismo ao retirar o sexo da esfera natural, atribuída pelos gregos e romanos, para inserir na esfera cultural dando um lugar preciso na história da salvação. Sendo assim, o cristianismo se afirmou como religião que valorizou o casamento e a castidade como vias espirituais (p.4-5) introduzindo uma possibilidade de escolha: casamento ou castidade perpétua, situação não encontrada, por exemplo, no mundo romano.

No que toca ao matrimônio uma das maiores alterações atribuídas ao cristianismo refere-se à questão da indissolubilidade. Ao declarar o vínculo matrimonial indissolúvel, uma vez que este não poderia ser desfeito por motivo de esterilidade como comumente acontecia no mundo romano, à religião cristã passaria a conceber a ligação entre os esposos como uma ligação de amor (p.15). Do ponto de vista teológico, a indissolubilidade do vínculo matrimonial nasceria da participação terrestre em um mistério divino de amor indissolúvel, aquele entre Cristo e a Igreja, representado segundo Agostinho, da transformação da água em vinho nas Bodas de Canaã (p.18). Dessa maneira algo que foi instituído por Deus não poderia ser desfeito pelos homens diante de qualquer motivo. Essa assertiva, em consonância com a perspectiva assumida por outros autores como Jack Goody na sua obra, Família e casamento na Europa, seria um dos primeiros argumentos trabalhados pela Igreja Católica para trazer o matrimônio para seu controle já que até então este competia ao Estado e as linhagens.

Outra inovação do cristianismo em matéria de sexualidade se relaciona com a possibilidade da castidade perpétua. As autoras 
destacam que tal caminho oferecia, especialmente às mulheres, uma possibilidade não existente até então. Os autores da Patrística, ao realçar a castidade como via de ascensão espiritual e como estágio superior ao casamento, teriam atraído grande número tanto de homens como de mulheres. No caso delas, oferecia como atrativo a possibilidade de escapar de maridos indesejáveis, da morte prematura no parto, bem como poderia significar a anulação da diferença biológica que lhe renderia igualdade aos homens. Já no que diz respeito ao celibato masculino, especialmente dos padres, a valorização da castidade precedeu em muito tempo a imposição da Igreja que viria acontecer com a Reforma Gregoriana. Essa constatação abre um precedente muito instigante para uma discussão ainda hoje presente no mundo católico: o celibato do clero seria originário de uma escolha individual e não uma imposição da Igreja por conta de um suposto ódio ao sexo.

No segundo capítulo Eros e santidade as autoras dão prosseguimento a discussão dos temas relativos à castidade e a sexualidade conjugal e sua transposição no universo dos signos, mitos e imagens sacras. Assim, reiteram como a cultura cristã usou por séculos símbolos e imaginários, muitos deles povoados de referências sexuais, para tratar da ligação entre a alma e Deus. Particularmente merece relevo a presença da literatura do Cântico dos Cânticos, texto bíblico permeado por referências de amor, bastante difundido nos meios intelectuais cristãos e que teria inspirado a arte e a literatura medieval. Muitas das referências amorosas que permeavam o universo sacro foram censuradas no contexto das Reformas, especialmente por conta de um surto de moralismo, emanado sobretudo dos meios protestantes que consideravam a Igreja Católica "permissiva" em determinados aspectos relativos à moral.

Em relação ao tema da castidade no universo sacro as autoras dão relevo a importância do culto mariano e a complexa identidade da virgem-mãe carregada de simbolismos, do qual é necessário exa- 
minar com atenção para compreender o estatuto da sexualidade na tradição cristã (p.62). Problematizam a ideia de que a virgindade de Maria ocuparia lugar central na construção da teologia cristã como argumento central para sublinhar a natureza humana e divina de Cristo, bem como para compreender o modelo assexuado de santidade. Por outro lado, destacam a desvalorização da figura de José até praticamente o fim do período medieval. Teria sido o século XVI, com o Concílio de Trento, a promover a Sagrada Família como modelo a ser imitado e, consequentemente, a difusão do culto a São José. Tal ação que glorificou personagens castos como exemplos à serem imitados, conjuntamente a adoção de códigos morais mais rígidos teriam contribuído para a desvalorização da sexualidade conjugal.

No mundo medieval referências ao corpo e ao sexo não só estiveram no centro dos debates teológicos como, por exemplo, a ampla e imensa discussão dos dias proibidos para a prática sexual, mas povoaram a arte, os textos literários, e atingiram até mesmo o universo das relíquias, à exemplo do prepúcio de Jesus conservado na Igreja de São João em Latrão (p.99).

No capítulo seguinte intitulado $O$ controle e a norma as autoras retomam a discussão sobre o casamento, bem como o lugar do sexo no seu interior. A discussão do casamento, sobretudo deste como sacramento foi objeto de intensos e acalorados debates desde a Antiguidade Tardia. Porém, foi durante a Reforma Gregoriana que as discussões se intensificaram. Teria sido nesse momento que a Igreja vem consolidar seu poder em um domínio que até então vinha sendo praticado como ato privado, a luz das tradições romanas e germânicas. Os usos consuetudinários advindos dos costumes germânicos que previam o divórcio, o concubinato e o rapto bem como as uniões consanguíneas foram alvos de intensos ataques por parte dos teólogos que cada vez mais propuseram o aspecto voluntário do matrimônio, numa tentativa de sobrepor o poder clerical ao controle das famílias e de eliminar as uniões entre parentes. Da mesma forma, acabar 
com a desordem produzida pelas uniões movidas por interesses. A castidade também teria sido um aspecto no qual a Igreja Católica teria valorizado o consenso.

O Concílio de Trento vem reforçar o casamento como sacramento, bem como a superioridade do estado de castidade e virgindade. Mas, a reforma mais significativa de Trento, que reforçou os domínios da Instituição Católica nesse tema, refere-se ao caráter público da cerimônia do casamento. Este deveria ser celebrado in facie Ecclesiae na presença de um padre e de testemunhas e nem a coabitação nem a consumação deveriam vir antes da benção do padre. Tal decreto contribuiria para reiterar a atribuição exclusiva da Igreja na realização tanto da cerimônia nupcial como da normatização da sexualidade matrimonial.

A teologia moral que se desenvolveu no contexto das Reformas Religiosas teria contribuído de maneira significativa para um processo de disciplinamento da moral sexual com a interiorização de normas e preceitos de culpa e de responsabilidade, do lícito e não lícito. Nesse processo de consolidação de uma consciência íntima, a ascensão da confissão auricular teve papel fundamental. Era através da confissão que o processo de culpa poderia ser redimido por meio de uma doutrina da penitência (p.126).

O período moderno teria sido marcado pela formatação de um discurso bastante rígido no que toca a sexualidade suplantando uma relativa tolerância até então existente, bem como a presença de figuras, símbolos e imaginários com conotações sexuais no universo sacro.

Segundo as autoras o autocontrole seria um termo que definiria bem o homem moderno. As normas morais descritas por Norbert Elias como elementos importantes do processo civilizador, teriam sido gestados no interior do cristianismo, do qual já as ordens monásticas teriam tido papel muito importante ao impôr uma batalha contra a carne e as suas pulsões. A elaboração de uma tratadística do 
pecado, da culpa, das fraquezas do corpo, relacionadas aos domínios da sexualidade, bem como sua remissão por meio de uma pedagogia do perdão, na qual a confissão ocupou lugar especial, teria contribuído para um maior controle da Igreja sobre seus fieis e da interiorização de normas e preceitos a partir daquele momento.

O quarto capítulo intitulado $O$ disciplinamento impossivel é dedicado às preocupações da Igreja Católica em relação à sexualidade não conjugal e não reprodutiva. Assim perpassam os escritos católicos no que toca aos chamados “desvios sexuais". Se até então, as autoras haviam focado na questão da heterossexualidade, ou seja, especialmente no lugar do sexo no interior do casamento, nessa parte há espaço para a discussão da sexualidade não conjugal. Destacam que, apesar da reprovação católica do sexo fora do matrimônio, existia uma vasta zona de tolerância em relação a sodomia, por exemplo, ou ao sexo homossexual. Tal constatação é feita com base em dados numéricos e estudos específicos de outros autores que demonstram que as condenações teriam sido pequenas se comparadas à sua real prática. Também chamam atenção para o cuidado que deve ser tomado em relação ao uso do termo homossexual. Seria particularmente difícil propor uma história de longo período da homossexualidade porque na elaboração jurídica e teológica inexistia a figura do homossexual. Embora trate-se de uma sociedade marcadamente cristã, no Ocidente medieval, a convivência com certas práticas sexuais (iniciáticas muitas vezes), apesar de condenadas, não colocava grandes desafios as identidades sexuais socialmente reconhecidas (p.169-170).

Na visão das autoras, à condenação aos atos não conjugais como a masturbação, a sodomia, o bestialismo, o adultério e os modos considerados "inadequados" de copular ocuparam o cerne das preocupações dos teólogos porque representariam muito mais que fraquezas morais, ausência de controle ou pecado, mas porque dessacralizariam o sexo. Não foi a toa que tratadistas católicos elaboraram uma complicada arquitetura de direitos e deveres em torno da ideia 
do débito conjugal, cuja ideia inicial remonta a Paulo o apóstolo, bem como a necessidade das plenas faculdades sexuais para a realização de um casamento. A não consumação de um matrimônio por conta da impotência de um dos cônjuges, desde que comprovada, garantiria a anulação de um casamento e a possibilidade de novas núpcias, uma das poucas ocasiões em que uma união matrimonial poderia ser desfeita. Assim, o sexo ocuparia lugar primordial no casamento por se tratar de um aspecto da revelação do amor divino.

O quinto capítulo O fim do monopólio se debruça sobre as transformações pela qual a sociedade ocidental passou a partir do século XVIII, bem como as mudanças que se delinearam em relação ao casamento e ao sexo. A partir do século XIX o discurso sobre a sexualidade cada vez mais passou às competências científicas (médicas, biológicas, antropológicas, psicanalíticas) que negaram à Igreja o direito de impor normas sobre a sexualidade, esvaziando o significado espiritual do sexo. Os tratados morais foram substituídos pela literatura científica e as competências em relação ao matrimônio deixaram de pertencer à alçada da Igreja para passar as mãos do Estado. A introdução do casamento civil e do divórcio seriam exemplos desse processo. Uma nova sensibilidade teria se desenvolvido em relação ao casamento, ao sexo e ao amor reduzindo a ideia de união espiritual, bem a jurisdição da Igreja nesse assunto.

Os estudos científicos passaram a ganhar espaço a partir do século XVIII e coube à ciência desvendar os aspectos fisiológicos e morfológicos do corpo. Assim criou métodos e categorias não só para diferenciar machos e fêmeas, mas para definir comportamentos, bem como os limites entre normalidade e anormalidade (p.221). A natureza não seria mais vista como um dom de Deus, mas como resultado de um processo contínuo de evolução. Natureza essa que precisaria ser conhecida para afastar/segregar aquilo que era considerado incurável. Com o desenvolvimento dos saberes científicos, a cura teria substituído a redenção e a Igreja Católica 
viu progressivamente se esgotar um instrumento que havia sido decisivo no domínio das consciências.

A sexualidade passou a ser concebida como algo de interesse público, com a ingerência cada vez maior do Estado. Nessa perspectiva a masturbação e a homossexualidade passaram a ser encaradas como doenças, necessitando o seu estudo científico para alcançar formas de cura. Na mesma direção, o sexo mercenário passou a ser combatido como forma de sanear a sociedade.

O período foi também marcado por mudanças estruturais da população. A revolução demográfica do século XIX e início do século XX também veio acompanhada de uma revolução ideológica e cultural. Os progressos tecnológicos possibilitariam a escolha do momento adequado para procriar, bem como o número de filhos desejados. A difusão dos métodos anticoncepcionais, o crescimento de movimentos anticlericais, de propaganda do ateísmo, do livre pensamento e do evolucionismo que sustentavam a necessidade de uma seleção eugênica para a evolução da espécie humana teria obrigado a hierarquia eclesiástica a construir e afinar novos instrumentos para gestar com eficácia os comportamentos sexuais de seus fieis (p.231233). Tais instrumentos são objeto do último capítulo.

No sexto e último capítulo Competições e Conflitos as autoras discutem as respostas dadas pela Igreja Católica frente à propaganda neomalthusiana e as proposições eugênicas das primeiras décadas do século XX que valorizaram uma moral calcada no indivíduo como condição para alcançar a felicidade humana. Em uma sociedade já imersa em valores liberais e democráticos, que não precisava mais procriar um alto número de filhos para garantir a sobrevivência da família e do grupo social abria-se a possibilidade de mudar as regras sociais dos comportamentos sexuais impostos pela moral cristã, bem como dissociar procriação de sexualidade e procriação de matrimônio (p.239). Tais mudanças teriam abertos problemas até então não enfrentados pela Igreja. 
O processo de secularização não teria colocado em xeque apenas a moral sexual cristã, mas também a legitimidade da Igreja Católica em falar de sexo. $\mathrm{O}$ advento do discurso psicanalítico, bem como o ataque dos anticlericais à confissão, teria contribuído de forma substancial para minar o seu poder em matéria de sexualidade. Como consequência, os confessionários foram sendo substituídos progressivamente pelo divã do psicanalista.

As novas descobertas científicas e as diversas críticas que a Igreja vinha sofrendo por todos os lados não teriam provocado uma alteração imediata da concepção católica de sexualidade. Ao contrário a Igreja reforçou sua posição tradicional que pode ser verificada, por exemplo, no Código de Direito Canônico de 1917 do papa Bento XV, cujo artigo 1013 confirmou como finalidade principal do matrimônio a procriação e a educação dos filhos. Da mesma forma, as proposições neomalthusianas de controle de natalidade foram rebatidas, tanto que em 1930 o papa Pio XI na encíclica Casti Conubii confirmou a condenação a qualquer forma de intervenção humana na natalidade que se oponha a lei natural. Ademais, manteve sua posição tradicional ao recorrer principalmente a Agostinho e sua visão pessimista da sexualidade (p.255-260).

A descoberta da pílula anticoncepcional teria aberto um novo capítulo para a prática da sexualidade colocando problemas inéditos à Igreja Católica. Às mulheres não só poderiam escolher o momento desejado para serem mães, mas também tornou possível separar sexualidade, do amor e da família como havia sido sempre possível somente aos homens (p.261-263). Algumas mudanças foram sinalizadas quando da publicação da Gaudium et Spes por João XXIII que rompeu com a teoria do casamento como remédio para a concupiscência e se esforçou para restituir o valor da vida sexual dos esposos e o diálogo entre os corpos. Entretanto, a vitória da ala minoritária e conservadora do corpo eclesiástico, manteve o posicionamento tradicional que foi referendada com a encíclica de 
Paulo VI Humanae Vitae de 1968 que confirmou com substância e sem ambiguidades os ensinamentos tradicionais da Igreja Católica.

Ao examinar o desenvolvimento do discurso sobre sexualidade na cultura cristã as autoras destacam as contradições e a posição ambígua da Igreja Católica no decorrer dos séculos. Apresentam uma perspectiva nova de análise procurando compreender o lugar do sexo na cultura cristã, escapando as análises superficiais e esteriotipadas que enxergam no discurso católico a sexofobia. Entendem que o lugar comum que vincula um suposto ódio da Igreja em relação ao sexo é resultado de incompreensões históricas, em geral forjadas pelos inúmeros críticos da Instituição.

Ao atribuir um sentido espiritual ao ato sexual o cristianismo teria se diferenciado das demais religiões monoteístas. Assim, o argumento teológico da Encarnação, bem como a ideia do corpo como templo do Espírito Santo teria valorizado o sexo. Se este é algo sagrado, deveria ser regulamentando e praticado somente dentro das premissas de uma sexualidade conjugal. Este lugar sagrado e seus importantes significados simbólicos e espirituais poderiam ser verificados na maneira como a cultura cristã representou os elementos sexuais em seus vários aspectos - artístico, litúrgico, místico, teológico - ao menos até o século XVI. A Igreja sempre privilegiou a possibilidade de escolha - entre vida religiosa e vida espiritual como uma via individual para atingir Deus. Assim as autoras lançam a tese de que a concepção cristã-católica, no que toca ao universo espiritual, sempre pressupôs igualdade entre homens e mulheres. Da mesma forma, o foco de preocupações da Igreja em relação ao sexo na maioria das vezes recaiu sobre os homens, e não as mulheres, considerados mais propensos à tentação. Basta analisar as reflexões em torno dos pecados do sexo, que vão da masturbação a sodomia, que tem como centro de discussões muito mais o universo masculino.

Teria sido o período moderno marcado pela difusão da palavra escrita ocupando lugares da imagem e do ritual, assim como a supre- 
macia do direito canônico sobre as questões sexuais e a afirmação da confissão como instrumento de controle da sexualidade, a marcar uma viragem nas maneiras de conceber o sexo. Culpa, autocontrole, perdão, pecado, penitência são ideias que teriam passado a permear o universo católico com mais força. Com o desenvolvimento da ciência médica e o triunfo do individualismo cresceu a oposição entre o governo da sexualidade por parte da religião e a satisfação dos desejos hedonistas pregado pelas ideologias modernas. A visão católica construída ao longo de séculos que inseriu os comportamentos sexuais no interior do caminho pessoal de santificação, criado para organizar um sistema moral, foi perdendo espaço principalmente no correr do século XX. A posição da Igreja, em especial das últimas décadas, de tentar resgatar os significados espirituais da sexualidade tem encontrado obstáculos em uma sociedade secularizada que cada vez mais entende que os comportamentos sexuais sejam da alçada do indivíduo. Finalizam as autoras, talvez seja o momento de pensá-lo também como questão do coletivo.

A associação de uma abordagem histórico-teológica do tema da sexualidade traz uma contribuição inédita à historiografia dos estudos de história do cristianismo. Fica o convite para a leitura de uma obra instigante que em muito contribui para iluminar aspectos das relações tão controversas entre Igreja e sexualidade.

Recebido em 17 de novembro de 2014 Aprovado em 27 de outubro de 2015 